\title{
Total solids-retention in activated sludge: modelling and simulation
}

\author{
C. Fall ${ }^{1}$, A. Jiménez-Zárate ${ }^{1}$, C. Martínez-García ${ }^{1}$, M. T. Olguín ${ }^{2}$, \\ E. Millán-Lagunas ${ }^{1} \&$ Y. Comeau ${ }^{2}$ \\ ${ }^{1}$ Universidad Autónoma del Estado de México, CIRA-UAEM, México \\ ${ }^{2}$ Instituto Nacional de Investigaciones Nucleares (ININ), México \\ ${ }^{3}$ École Polytechnique de Montréal, Canada
}

\begin{abstract}
Research on new ways for minimizing the residues generated in biological wastewater treatment has been encouraged within the context of activated sludge models (ASM). One of the methods used for minimizing sludge is through the elimination of traditional sludge wastage (WAS), while build-up of the inert solids in aeration tanks and is avoided by other means; the development of fine screens to remove the inert particulate organic fraction (XI), hydrocyclones for inorganic suspended solids (ISS) and different kinds of on-line digesters to further biodegrade the endogenous residues (XP) via the return activated sludge line (RAS). In this research, a model and a simulation program was developed, which was able to mimic the apparent behavior of such activated sludge variants with low-solids-production (LSP-AS). This model is an extended ASM1 assuming a small first order biodegradation constant for XP $(\mathrm{kXP}=0.007 \mathrm{~d}-1)$ and black boxes representing the XI and ISS inerts-removal. The simulations depict the way that different components of solids build up in the aeration tanks when traditional activated sludge (C-AS) is operated at very high solids retention times $(>100 \mathrm{~d})$. The simulations showed that the C-AS process could, hypothetically, be replaced by LSP-AS variants with similar levels of active biomass and of mixed-liquor suspended solids. The kXP was approximately $0.007 \mathrm{~d}-1$ and, for this case, at least $2 \%$ (and $6 \%$ ) of the RAS flow had to be sieved (and digested, respectively), to avoid the accumulation of XI, ISS and XP. Furthermore, the size of the on-line digester was about twice the volume of the aeration tank.
\end{abstract}

Keywords: Aquasim, ASM1, endogenous residues, inerts, minimization. 


\section{Introduction}

Among the new concepts put forward in recent years in wastewater treatment, there are modified activated sludge systems, with low sludge production (LSPAS) or total-solids retention. Instead of producing a lot of sludge before stabilizing it off-line, the new proposals seek to reduce the generation of solids from the source, inside the water treatment lines [1].

Research on new ways for minimizing the residues was encouraged by the context of the activated sludge models (ASM, 1, 2 and 3; Henze et al. [2]). Based on these models, the main components of biological secondary sludge are heterotrophic biomass $\left(\mathrm{X}_{\mathrm{H}}\right)$, endogenous residues from decay $\left(\mathrm{X}_{\mathrm{P}}\right)$, particulate inert organic matter and inorganic suspended solids ( $\mathrm{X}_{\mathrm{I}}$ and ISS).

The principle of some of the LSP systems is to eliminate the traditional waste activated sludge stream (WAS) and to selectively remove the three "inert" fractions $\left(X_{I}\right.$, ISS and $\left.X_{P}\right)$, which otherwise would accumulate in the aeration tanks. One of the know LSP-AS systems is the Cannibal ${ }^{\mathrm{TM}}$ process [3, 4]. Part of the Return Activated Sludge flow (RAS) is passed through fine sieves for removing $\mathrm{X}_{\mathrm{I}}$ (typically toilet paper and hairs [5]) and through hydrocyclones for grit removal (ISS [6]). An on-line digester, installed in the RAS line, is then used to further biodegrade the biomass residues, $\mathrm{X}_{\mathrm{P}}$, considered before as completely inert [7]. There are many other LSP-AS processes known under different names: OSA for oxic-settling-anoxic process [8, 9], BIMINEX [10], SSR for Side-Stream-Reactor [11, 12], etc. On-line Digesters Units (RAS-DU) installed through the RAS line are used in the different proposals, which have aerobic, anaerobic, hypoxic (HDU for Cannibal ${ }^{\mathrm{TM}}$ ) or alternating conditions. Different authors claim a sludge reduction of up to $60 \%$ for the LSP-AS process $[3,4]$ compared to the traditional activated sludge process (C-AS).

In conventional activated sludge (C-AS), a continuous or intermittent wasting of the portion of biosolids is required in order to maintain an acceptable level (not too high) of the Mixed Liquor Total Suspended Solids (MLTSS) in the aeration tank [13]. However, when the traditional WAS is drastically reduced $(\mathrm{SRT}>100 \mathrm{~d})$ or totally cancelled (total solid retention), alternative solid wasting or degradation is needed. Instead of putrescible rejects, the claim of the LSP-AS process is to produce inert sludge (from screens and cyclones) and in smaller quantities. It must be noted that the referred SRT, as computed, do not take into account the solids retired from the screen and the HC; the SRT holds for the solids purged through the traditional way (non-stabilized WAS).

The literature on the modeling and simulation of the LSP-AS is very scarce. Previously, Johnson et al. [4] reported modeling work on the Cannibal ${ }^{\mathrm{TM}}$ process using a home-built program based on the ASM2d model. ASM2d was modified by adding a new process, namely the anaerobic hydrolysis of the endogenous biomass products $\left(\mathrm{X}_{\mathrm{P}}\right)$, to particulate biodegradable fraction $\left(\mathrm{X}_{\mathrm{S}}\right)$.

Ultimately, Jones et al. [14] proposed a first order model for the decay of $\mathrm{X}_{\mathrm{P}}$, finding a constant of $0.0075 \mathrm{~d}^{-1}$. Ramdani et al. [7] confirmed that the endogenous residues from biomass decay $\left(\mathrm{X}_{\mathrm{P}}\right)$ could be further biodegraded, being a first order kinetic reaction, of which the decay constant, $\mathrm{k}_{\mathrm{XP}}$, is between 
0.005 and $0.012 \mathrm{~d}^{-1}$. In a review [15], the value of $0.007 \mathrm{~d}^{-1}$ was suggested as a good estimate of the first order constant for $X_{P}$ degradation under aerobic conditions. In this knowledge, the order of value of the degradation rate of $X_{P}$ is a step forward for evaluating the feasibility of total sludge retention processes, which means operating activated sludge processes, practically without wastage $(\mathrm{SRT}>100 \mathrm{~d})$.

The objective of the research was to develop a modified-ASM1 based model that is capable of mimicking the behavior of the LSP-AS processes in Aquasim, and of evaluating the reaction volumes and flow needs of the extra processes.

\section{Material and methods}

The first phase of the study was based on the classical approach of Metcalf and Eddy [13] using an Excel spreadsheet to illustrate the dependence between the accumulation of the solids in the mixed liquor and sludge retention time (SRT) in the conventional activated sludge process (C-AS). In the second phase, gradual modeling was performed in Aquasim [16, 17] for SRTs from 25 to $>100 \mathrm{~d}$ and for both variants, the C-AS and LSP-AS process (sieve + hydrocyclone + on-line RAS digester unit) was applied.

\subsection{Wastewater Treatment Plant case (WWTP)}

The case studied is initially a conventional activated sludge plant with a flow rate of $10,000 \mathrm{~m}^{3} / \mathrm{d}$. The operational data is shown in Table 1 . The influent contained $18 \mathrm{mg} / \mathrm{L}$ ISS (inorganic suspended solids) and $300 \mathrm{mg} / \mathrm{L}$ total COD. All the input parameters required to perform ASM1 simulations are given in Table 2. Concerning the Metcalf and Eddy [13] equations used in parallel, the necessary concentrations data is the total biodegradable substrate $(\mathrm{S} 0=240 \mathrm{mg} / \mathrm{L} \mathrm{COD}$, represented by the sum $\mathrm{X}_{\mathrm{S}}+\mathrm{S}_{\mathrm{S}}$ ) and the ISS of the influent (or TSS minus VSS of the influent).

To simulate the modified activated sludge variant (LSP-AS), a sieve, a hydrocyclone and a digester were inserted in the RAS line. Initially, the volume of the on-line digester unit (RAS-DU unit) was $1500 \mathrm{~m}^{3}$ with an RAS inflow of $100 \mathrm{~m}^{3} / \mathrm{d}$, in conformity with the design criteria of $15 \mathrm{~d}$ SRT suggested by Johnson et al. [4]. Concerning the physical unit processes, at the beginning, the flow fed to the hydrocyclone and screen line was set at $10 \%$ of the RAS flow and the latter was increased according to the desired levels of $X_{I}$ and ISS in the aeration tank.

Table 1: Flow rates and dimensions of the wastewater treatment plant.

\begin{tabular}{lccc}
\hline Operational Data & Symbols & Values & Units \\
Influent flow rate & Qin & 10,000 & $\mathrm{~m}^{3} / \mathrm{d}$ \\
Recirculated Activated Sludge (RAS) flow & Qrec & 3,300 & $\mathrm{~m}^{3} / \mathrm{d}$ \\
Temperature & $\mathrm{T}$ & 20 & ${ }^{\circ} \mathrm{C}$ \\
Sludge retention time (Design) & SRT & 15 & $\mathrm{~d}$ \\
Aeration tank volume & $\mathrm{V}_{\text {Reactor }}$ & 6000 & $\mathrm{~m}^{3}$ \\
Settler volume & $\mathrm{V}_{\text {Settler }}$ & 400 & $\mathrm{~m}^{3}$ \\
\hline
\end{tabular}


Table 2: Characteristics of the influent (ASM1 nomenclature).

\begin{tabular}{lccc}
\hline \multicolumn{1}{c}{ Components } & Symbol & Valor & Units \\
\hline Inert soluble organic matter & $\mathrm{S}_{\mathrm{I}}$ & 20 & $\mathrm{~g} \mathrm{COD} / \mathrm{m}^{3}$ \\
Readily biodegradable organic matter (soluble) & $\mathrm{Ss}$ & 70 & $\mathrm{~g} \mathrm{COD} / \mathrm{m}^{3}$ \\
Inert particulate organic matter & $\mathrm{X}_{\mathrm{I}}$ & 40 & $\mathrm{~g} \mathrm{COD} / \mathrm{m}^{3}$ \\
Slowly biodegradable organic matter (particulate) & $\mathrm{Xs}$ & 170 & $\mathrm{~g} \mathrm{COD} / \mathrm{m}^{3}$ \\
Heterotrophic active biomass & $\mathrm{X}_{\mathrm{H}}$ & 0 & $\mathrm{~g} \mathrm{COD} / \mathrm{m}^{3}$ \\
Autotrophic active biomass & $\mathrm{X}_{\mathrm{A}}$ & 0 & $\mathrm{~g} \mathrm{COD} / \mathrm{m}^{3}$ \\
Biomass residues from lysis & $\mathrm{X}_{\mathrm{P}}$ & 0 & $\mathrm{~g} \mathrm{COD} / \mathrm{m}^{3}$ \\
Dissolved oxygen (D.O.) & $\mathrm{S}_{\mathrm{Ox}}$ & 0 & $\mathrm{~g} \mathrm{COD} / \mathrm{m}^{3}$ \\
Nitrites and Nitrites (NO $\mathrm{NO}_{2}+\mathrm{NO}_{3}$ ) & $\mathrm{S}_{\mathrm{NO}}$ & 0 & $\mathrm{~g} \mathrm{~N} / \mathrm{m}^{3}$ \\
Ammonium nitrogen (N_NH ${ }_{4}^{+}+\mathrm{NH}_{3}$ ) & $\mathrm{S}_{\mathrm{NH}}$ & 18 & $\mathrm{~g} \mathrm{~N} / \mathrm{m}^{3}$ \\
Soluble biodegradable organic nitrogen & $\mathrm{S}_{\mathrm{ND}}$ & 5 & $\mathrm{~g} \mathrm{~N} / \mathrm{m}^{3}$ \\
Particulate biodegradable organic nitrogen & $\mathrm{X}_{\mathrm{ND}}$ & 10 & $\mathrm{~g} \mathrm{~N} / \mathrm{m}^{3}$ \\
Alkalinity & $\mathrm{S}_{\mathrm{ALK}}$ & 5 & $\mathrm{Mol} / \mathrm{m}^{3}$ \\
Inorganic Suspended Solids (=TSS-VSS) & $\mathrm{ISS}$ & 18 & $\mathrm{~g} \mathrm{TSS} / \mathrm{m}^{3}$ \\
\hline
\end{tabular}

\subsection{Mathematical models and equations}

With respect to the first method of calculation, the classical steady-state activated sludge equations were used, using the following kinetic and stoechiometric parameters: maximum specific substrate utilization rate, $\mathrm{k}=5 \mathrm{~g} \mathrm{COD} / \mathrm{gVSS} \mathrm{d}^{-1}$; heterotrophic yield, $\mathrm{Y}_{\mathrm{H}}=0.4 \mathrm{~g} \mathrm{SSV} / \mathrm{g}$ COD; decay rate, $\mathrm{k}_{\mathrm{d}}=0.18 \mathrm{~d}^{-1}$; substrate half saturation constant, $\mathrm{K}_{\mathrm{S}}=10 \mathrm{~g} / \mathrm{m}^{3} \mathrm{COD}$ and endogenous biomass fraction from decay, $\mathrm{f}_{\mathrm{P}}=0.27$. The equations were modified and extended from Metcalf \& Eddy [13]. The respective concentrations of the main sludge fractions $\left(\mathrm{X}_{\mathrm{H}}, \mathrm{X}_{\mathrm{I}}\right.$, $\mathrm{X}_{\mathrm{P}}$, ISS), the total sums (MLVSS, MLTSS, MLCOD) and the observed yield $\left(\mathrm{Y}_{\mathrm{obs}}\right)$ were calculated as function of the SRT.

For the steady state equations, as well as for the Aquasim program, different known ratios were used to be able to convert the concentrations from VSS, to TSS and COD and vice-versa. The considered values were the following: $\mathrm{icv}_{\text {bio }}=1.42 \mathrm{mg} \mathrm{COD} / \mathrm{mg} \operatorname{VSS}$ (for $\mathrm{X}_{\mathrm{H}}, \mathrm{X}_{\mathrm{P}}, \mathrm{X}_{\mathrm{A}}, \mathrm{X}_{\mathrm{S}}$ ); icvinfluent $=1.50 \mathrm{mg}$ $\mathrm{COD} / \mathrm{mg} \mathrm{VSS}$ (for $\mathrm{X}_{\mathrm{I}}$ from the influent); ivt bio $=0.92 \mathrm{mg} \mathrm{VSS} / \mathrm{mg} \mathrm{SST}$ (for $\mathrm{X}_{\mathrm{H}}, \mathrm{X}_{\mathrm{P}}, \mathrm{X}_{\mathrm{A}}$ ).

The simulation program was developed in Aquasim, based on ASM1 [2]. It has been modified by adding a new process for the aerobic degradation of the endogenous residues $X_{P}$ in the digester (Table 3). Based on recent researches $[7,14,15]$, the first order constant of $X_{P}$ decay was set to $k_{x p}=0.007 \mathrm{~d}^{-1}$. For the other 8 processes of the ASM1, the default values were used [2]. The dissolved oxygen concentration was made equal to $\mathrm{S}_{\mathrm{Ox}}=2 \mathrm{mg} / \mathrm{L}$ in the reactors.

As a flexible option in Aquasim, we chose to represent the process of traditional sludge wasting (WAS) as a simple reaction that removes mixed-liquor solids directly from the aeration tank (Table 3). 
Table 3: Definition of the additional processes used to extend the ASM1.

\begin{tabular}{|c|c|c|c|}
\hline Processes & $\mathrm{X}_{\mathrm{P}}$ & $\mathrm{X}_{\mathrm{J}}$ & Rate \\
\hline 1. Degradation of $\mathrm{Xp}$ & -1 & - & $k_{X P} \bullet X_{P}$ \\
\hline 2. Activated sludge wasting (WAS) & - & $-\mathrm{XJ}$ & $1 / \mathrm{SRT}$ \\
\hline
\end{tabular}

\subsection{Process diagram as implemented in Aquasim}

The flow sheet of the LSP-AS process was configured in Aquasim by defining the compartments (CSTR tanks) and links, as in Figure 1. The sludge return line (RAS) was modified by connecting two bifurcations transporting the concentrated solids to the digester (RAS-DU) on one side and to the physical treatments on the other (screen and hydrocyclone). The parts of the deviated flow were set through the fractions frQ-to-RAS-DU and frQ-to-Sc-Hc, defined with respect to the total RAS flowrate from the settler $\left(\mathrm{Q}_{\mathrm{RAS}}\right.$, Table 1). When frQ-toRAS-DU and frQ-to-Sc-Hc are set to 0 , the process becomes that of a traditional activated sludge (C-AS).

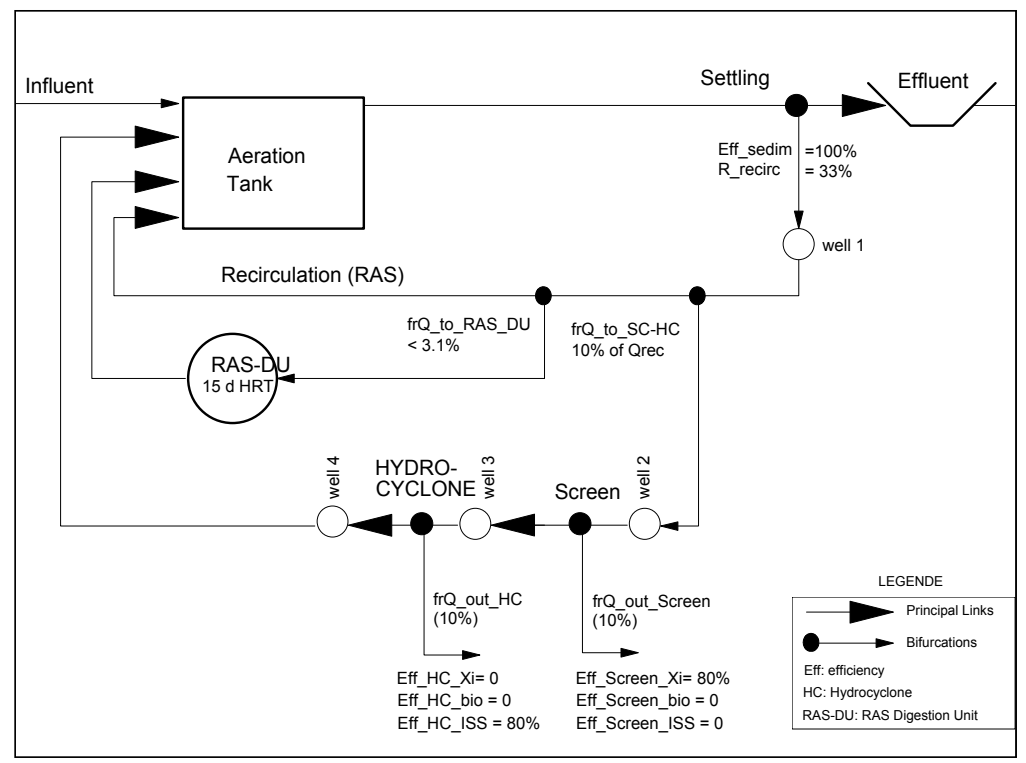

Figure 1: Diagram implemented in Aquasim to simulate the LSP-AS process.

Black boxes were defined in Aquasim to simulate the physical processes as a point of material separation (settler, screen and hydrocyclone, Figure 1). The settler point-model was set with $100 \%$ removal efficiency (Eff-sedim). For the screen (SC) and hydrocyclone (HC), selective separation of the solids was 
obtained by defining three types of efficiencies, depending on the types of solids: $\mathrm{X}_{\mathrm{I}}$ removal efficiency (Eff_X $\mathrm{X}_{\mathrm{I}}$ ); ISS removal efficiency (Eff_ISS); efficiency on the biological materials $\mathrm{X}_{\mathrm{H}}, \mathrm{X}_{\mathrm{P}}, \mathrm{X}_{\mathrm{S}}$ and $\mathrm{X}_{\mathrm{A}}$ (Eff_bio). Eff_bio was set to $0 \%$, while Eff_ $X_{I}$ and Eff_ISS were fixed at 80 and $\overline{0 \%}$ in the sieve, against 0 and $80 \%$ at the hydrocyclone (HC).

The final program implemented in Aquasim was endowed with a high flexibility, to allow its use to gradually explore different scenarios, ranging from the conventional activated sludge process (C-AS) to complete sludge retention (LSP-AS variant). Extended aeration C-AS may be simulated, just by closing the valves (frQ-to-RAS-DU and frQ-to-Sc-Hc $=0$ ) and changing the SRT to 25 days. To begin the mutation toward a low sludge production process (LSP-AS), first change SRT to $150 \mathrm{~d}$. To simulate the removal of $X_{I}$ and ISS through the sieve and HC, set also frQ-to-Sc-Hc at 0.1 ( $10 \%$ of the RAS). To add the digester and to be able to degrade $\mathrm{X}_{\mathrm{P}}$, fix frQ-to-RAS-DU $=0.0303$ (or $3.03 \%$ of the RAS flow as a first scenario). For the latter, several other scenarios may be tested with different digester volumes, HRTs and inflows.

\section{Results and discussion}

\subsection{Relation between the SRT and the sludge production in C-AS processes}

This analysis was conducted (steady-state equations) to illustrate some basic features of traditional activated sludge (C-AS). The variables related to the quality and quantities of sludge in the reactor were calculated at different SRTs (Figure 2). At 25 days SRT, for instance, the composition of the mixed liquor in TSS would be $770 \mathrm{mg} / \mathrm{L} \mathrm{X}$ H, $980 \mathrm{mg} / \mathrm{L} \mathrm{X}, 1110 \mathrm{mg} / \mathrm{L} \mathrm{X}$ and $750 \mathrm{mg} / \mathrm{L}$ ISS, for a total of $3610 \mathrm{mg} / \mathrm{L}$ MLTSS or $2720 \mathrm{mg} / \mathrm{L}$ MLVSS. The ivt and icv ratios of the mixed liquor as a whole, in this case, would be $0.75 \mathrm{gVSS} / \mathrm{gTSS}$ and $1.45 \mathrm{gCOD} / \mathrm{g}$ VSS, while the net sludge production would be $0.36 \mathrm{mg}$ TSS per mg biodegradable COD (observed yield, Yobs). These results were verified and in total accordance with the predictions made in parallel with the simulation in Aquasim.

According to Figure 2(a), increasing the SRT would be one of the ways to reduce the sludge generated $\left(\mathrm{Y}_{\mathrm{obs}}\right)$. This strategy is already practiced in extended aeration activated sludge. For the case studied, increasing the operational SRT will decrease $\mathrm{Y}_{\text {obs }}$ from 0.51 to $0.3 \mathrm{~g}$ TSS/g COD. At high SRTs (> 50 d), the total concentration of solids (MLTSS, Fig. 2(b)) in the mixed liquor will be so high that it would be impossible to satisfactorily operate the process. It would be difficult to meet the aeration needs in an economic way.

Figure 2(b) also shows the detailed composition of the mixed liquors at different SRT. From a certain residence time ( $>20 \mathrm{~d})$, the concentration of active biomass $\left(\mathrm{X}_{\mathrm{H}}\right)$ reaches a plateau, which is dictated by the amount of substrate available in the influent. However, unlike the active biomass, the MLTSS continue to increase sharply with the SRT due to the continuing accumulation of inerts in the mixed liquor $\left(\mathrm{X}_{\mathrm{I}}, \mathrm{X}_{\mathrm{P}}, \mathrm{ISS}\right)$. 

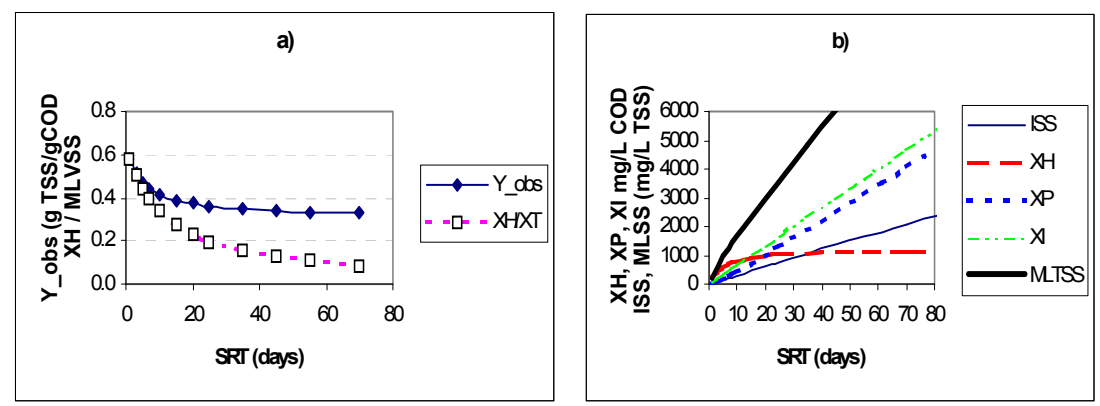

Figure 2: a) Sludge production of C-A; b) Composition of the sludge.

In summary, the analysis performed in this section clearly shows the functional requirements of the activated process processes operated with low active biomass wasting, i.e. at high SRTs or complete solids retention. The needs are to minimize the amount of putrescible waste sludge, while maintaining the mixed liquor concentrations at acceptable levels. The challenge in such processes (LSP-AS) would be to reach the selective removal or destruction of the components $\mathrm{X}_{\mathrm{I}}, \mathrm{X}_{\mathrm{P}}$, and ISS. This subtends the logic in the Cannibal ${ }^{\mathrm{TM}}$ process for example $[3,4]$, with a sieve to remove $X_{I}$, hydrocyclone to separate the ISS, and a digester to degrade $X_{P}$.

\subsection{Simulation of the C-AS process in Aquasim (from 25 to $150 \mathrm{~d}$ SRT).}

Simulations were performed on Aquasim (Figure 3) for the conventional activated sludge (C-AS) at $25 \mathrm{~d}$ SRT (extended-aeration), and then at $150 \mathrm{~d}$ (which in practice represents a hypothetical process operated without purging, i.e. no WAS). The area of interest is where the curves reach the steady state plateau.
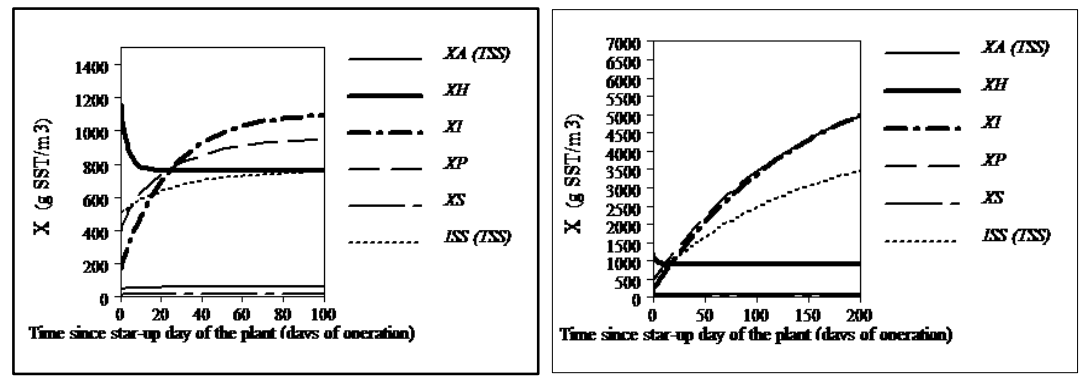

Figure 3: $\quad$ Mixed Liquor composition at $25 \mathrm{~d}$ SRT (left) and $150 \mathrm{~d}$ (right).

At 25 days SRT, the conventional activated sludge process works with concentration levels that are stable and acceptable, for all the mixed liquor components (Fig. 3 left, $3600 \mathrm{mg} / \mathrm{L}$ MLTSS and $750 \mathrm{mgTSS} / \mathrm{L}$ active biomass $\mathrm{X}_{\mathrm{H}}$ ). At $150 \mathrm{~d}$ SRT (Fig. 3 right), the active fraction is $890 \mathrm{mg} / \mathrm{L} \mathrm{TSS}$, not too 
different from the previous value (at $25 \mathrm{~d}$ ). In contrast, $\mathrm{X}_{\mathrm{I}}, \mathrm{X}_{\mathrm{P}}$ and ISS, and thereby the MLTSS in the mixed liquor, tend to accumulate, ultimately reaching unsustainable high levels ( $>10,000 \mathrm{mg} / \mathrm{L}$, Fig. 3 right). From this moment, it seems clear that all C-AS that claim to be able to run in complete solid retention need additional processes to remove the excess $X_{I}, X_{P}$ and ISS (not necessarily the $\mathrm{X}_{\mathrm{H}}$ ).

\subsection{Simulation of the effects of the screen and hydrocyclone}

From this stage, the system in this study is a modified activated sludge system (LSP-AS) equipped with a screen and hydrocyclone and is operated at $150 \mathrm{~d}$ SRT (i.e. practically, with the WAS valve closed).

By adding the screen and hydrocyclone, the inert solids levels drop abruptly to around $250 \mathrm{mg} / \mathrm{L}$, with a flow fraction lower than $10 \%$ (of the RAS flow). The concentration of $\mathrm{X}_{\mathrm{I}}$ and ISS in the reactor may be lowered at the same values or less to that existing in the standard C-AS operated without sieves at $25 \mathrm{~d}$ SRT (1110 mg/L X $X_{I}$ and $750 \mathrm{mg} / \mathrm{L}$ ISS). An frQ-to-Sc-Hc of $2 \%\left(\right.$ or $63 \mathrm{~m}^{3} / \mathrm{d}$ ) applied to the LSP-AS process, operated at 150 days SRT (closed WAS), is enough to achieve the above desired levels.

Figure 4 shows the composition of the mixed liquor over time, when the modified process is operated with a sludge age of 150 days (practically without purge) and when about $2 \%$ of the recirculation flow rate (RAS) is treated through the screen and hydrocyclone.

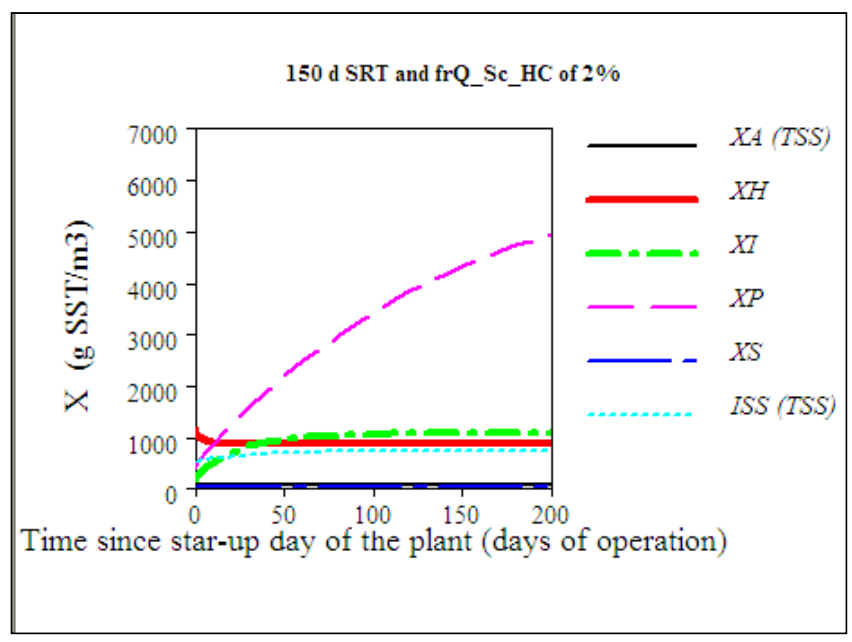

Figure 4: $\mathrm{X}_{\mathrm{I}}$ and ISS under control in the aeration tank.

In contrast with the behavior previously noted in Figure 3 (right), all the fractions $\left(X_{I}, I S S, X_{H}, X_{A}\right.$ and $X_{S}$ ) are now controlled (Figure 4) to a stable and acceptable level, except $X_{P}$ that would continue to accumulate for a moment (not yet treated). 


\subsection{Simulation of the degradation of $X_{P}$ in the on-line digester}

By installing an aerobic digester (RAS-DU) through the return activated sludge line of the LSP-AS process, it is sought to prevent the accumulation of $\mathrm{X}_{\mathrm{P}}$ and to maintain their concentration at an acceptable level. From a theoretical point of view, it is possible to estimate the $X_{P}$ removal efficiency that will be attained in the RAS-DU itself. In general, assuming a $1^{\text {st }}$ order kinetic rate law and assimilating the digester as a completely stirred tank reactor (CSTR), the relationship between the hydraulic residence time (HRT) and the efficiency (E) of the removal of $\mathrm{X}_{\mathrm{P}}$, between the inlet and outlet of the digester, is given by the following equation:

$$
E=\frac{H R T^{*} k_{X P}}{\left(1+H R T^{*} k_{X P}\right)}
$$
$\left(d^{-1}\right)$.

$\mathrm{E}$ is the efficiency for a given HRT, as a fraction; $\mathrm{k}_{\mathrm{XP}}$ : first order constant

Equation 1 enables the calculation of the $X_{P}$ removal efficiency that can be reached with a $\mathrm{k}_{\mathrm{XP}}$ magnitude value of about $0.007 \mathrm{~d}^{-1}$, as suggested in various studies $[7,14,15]$. For 15 days HRT, the value of $\mathrm{E}$ is 0.095 (or 9.5\%), against $30 \%$ at 60 days. In addition, for each HRT (and efficiency) the required volume can be calculated for different flow rates scenarios (frQ-to-RAS-DU). Different combinations of flow rates and digester volumes were tested in the simulator.

Beyond the efficiency in the digester, the final response of interest from the simulations is the level of $X_{P}$ that is reached in the aeration tank (between 3450 and $565 \mathrm{mg} / \mathrm{L} \mathrm{TSS}$, for the different scenarios tested). The LSP-AS scenarios that allow lowering these levels, up to near those of a standard C-AS satisfactorily operated at $25 \mathrm{SRT}$, are those reported in Table 4 (final residual $\mathrm{X}_{\mathrm{P}}$ around $950 \mathrm{mg} / \mathrm{L} \mathrm{TSS}$ ). The volume of the RAS-DU unit for the best scenarios was between 10,000 and $15,000 \mathrm{~m}^{3}$, which is 1.7 to 2.5 times the volume of the aeration tank, or 3 to 5 times the volume of an off-line stabilization digester.

Table 4: Heterotrophic biomass (XH) and MLTSS conc. in the aeration tank.

\begin{tabular}{|c|c|c|c|c|c|}
\hline & Scenario 1 & Scenario 2 & Scenario 3 & Scenario 4 & Reference \\
\hline frQ-to-RAS-DU $(\%)=>$ & $3.03 \%$ & $6 \%$ & $10 \%$ & $20 \%$ & no digester \\
\hline HRT of digester & $150 \mathrm{~d}$ & $60 \mathrm{~d}$ & $30 \mathrm{~d}$ & $15 \mathrm{~d}$ & C-AS process \\
\hline \multirow[t]{2}{*}{ Digester volume } & $15000 \mathrm{~m}^{3}$ & $11880 \mathrm{~m}^{3}$ & $9900 \mathrm{~m}^{3}$ & $9900 \mathrm{~m}^{3}$ & $25 \mathrm{~d}$ SRT \\
\hline & \multicolumn{5}{|c|}{ Concentrations (mg/L TSS) in the aeration tanks } \\
\hline $\mathrm{X}_{\mathrm{P}}$ & 991 & 914 & 970 & 930 & 950 \\
\hline $\mathrm{X}_{\mathrm{H}}$ & 680 & 565 & 473 & 350 & 755 \\
\hline MLTSS* & 3500 & 3300 & 3260 & 3070 & 3600 \\
\hline Digester TSS* & 9550 & 10330 & 11300 & 11130 & - \\
\hline
\end{tabular}


Another important aspect in the choice of the most viable alternatives is the impact of the on-line digester and its long HRTs, on the active biomass fraction $\mathrm{X}_{\mathrm{H}}$ (Table 4). More biomass decay will result in the RAS-DU unit. $\mathrm{X}_{\mathrm{H}}$ registered a sharp drop in scenarios 3 and $4(350$ and $470 \mathrm{mg} / \mathrm{L})$, compared to the value of $750 \mathrm{mg} / \mathrm{L}$ TSS that was prevailing in the reference scenario (C-AS at $25 \mathrm{~d}$ SRT). Between the other two remaining scenarios, the digester option 2 seems to be the best compromise (shorter HRT, $60 \mathrm{~d}$, and smaller volume). With scenario 2, the final levels of $X_{P}$ and MLTSS in the aeration tank are under control now (at about $900 \mathrm{mg} / \mathrm{L} \mathrm{TSS}$ ).

Finally, other aspects of the performance of the scenario 2 were studied. In average, the oxygen uptake rate (OUR) in the aeration basin was estimated to be $40 \mathrm{mg} / \mathrm{L} . \mathrm{h}$, including $30 \mathrm{mg} / \mathrm{L} . \mathrm{h}$ due to the nitrification. The COD and nitrogen concentrations levels in the treated effluent testify for good performance of the nitrification ( $>25 \mathrm{mg} / \mathrm{L} \mathrm{L} \mathrm{N}-\mathrm{NO}_{3}$ produced) and of the organic matter removal. The ammonia nitrogen $\left(\mathrm{S}_{\mathrm{NH}}\right)$ and the biodegradable organic matter $\left(\mathrm{S}_{\mathrm{S}}\right)$ were reduced to less than $2 \mathrm{mg} / \mathrm{L}$.

\section{Conclusions}

The modified ASM1 model, including a slow degradation process of the endogenous residues $X_{P}$ in a digester, combined with black-boxes representing the physical removal of the inerts ( $\mathrm{X}_{\mathrm{I}}$ and ISS), adequately reproduced the apparent behavior of activated sludge with low sludge production (LSP-AS).

According to the simulations performed, a conventional activated sludge process (C-AS) may be substituted by an LSP-AS process (sieve, HC and on-line RAS-digester) that would operate with similar levels of active biomass and MLTSS in the aeration basin.

For the studied wastewater influent and for a $\mathrm{k}_{\mathrm{XP}}$ value of about $0.007 \mathrm{~d}^{-1}$, at least $2 \%$ (and $6 \%$ ) of the RAS flow must be sieved (and digested, respectively), to avoid the accumulation of $\mathrm{X}_{\mathrm{I}}$, ISS and $\mathrm{X}_{\mathrm{P}}$. Also, the size of the on-line digester will be about twice the volume of the aeration tank.

The mathematical model implemented in Aquasim could serve as didactical, operational and research simulation tool for LSP-AS processes.

\section{Acknowledgement}

We would like to thank Consejo Nacional de Ciencias y Tecnología, CONACYT, México, for their financial support (\#152943).

\section{References}

[1] Low E.W. and Chase H.A. (1999). Reducing production of excess biomass during wastewater treatment. Water Res., 33(4), pp. 1119-1132. 
[2] Henze M., Gujer W., Mino T. and Van Loosdrecht M.V. (2000) Activated sludge models ASM1, ASM2, ASM2d and ASM3, IWA Publishing, London, p. 130.

[3] Novak J.T., Chon D.H., Curtis B.A. and Doyle M. (2007). Biological Solids Reduction Using the Cannibal Process. Water Environ. Res., 79 (12), pp. 2380-2386.

[4] Johnson B.R., Daigger G.T. and Novak J.T. (2008). The Use of ASM based Models for the Simulation of Biological Sludge Reduction Processes. Water Practice \& Technol., 3(3), IWA Publishing, p. 10.

[5] Ruiken C.J., Klaversma E. and van Loosdrecht M.C.M. (2011). Removal of toilet paper from influent of municipal wastewater treatment by sieves. Proceedings, 11th IWA Specialized Conference on Design, Operation and Economics of Large WWTP, 4-8 Sept. 2011, Budapest, Hungary. pp. 191-198.

[6] Mansour-Geoffrion M., Dold P.L., Lamarre D., Gadbois A., Deleris S. and Comeau Y. (2010). Characterizing Hydrocyclone Performance for Grit Removal From Wastewater Treatment Activated Sludge Plants. Minerals Engineering, 23(4), pp. 359-364.

[7] Ramdani A., Dold P., Gadbois A., Déléris S., Houweling, D. and \# Comeau Y. (2012). Biodegradation of the endogenous residue of activated sludge in a membrane bioreactor with continuous or on-off aeration. Water Res. 46 (9), pp. 2837-2850.

[8] Chudoba P., Chudoba J. and Capdeville B. (1992). The aspect of energetic uncoupling of microbial growth in the activated sludge process-OSA system. Water Sci. Technol. 26 (9-11), pp. 2477-2480.

[9] Saby S., Djafer M. and Chen G. (2003). Effect of low ORP in anoxic sludge zone on excess sludge production in oxic-settling-anoxic activated sludge process. Water Res., 37, pp. 11-20.

[10] Coma M., Rovira S., Canals J. and Colprim J. (2013). Minimization of sludge production by a side-stream reactor under anoxic conditions in a pilot plant, Bioresource Technol., 129, pp. 229-235.

[11] Chon D.H., Rome M., Kim Y. M., Park Y. M. and Park C. (2011). Investigation of the sludge reduction mechanism in the anaerobic sidestream reactor process using several control biological wastewater treatment processes. Water Res. 45 (18), pp. 6021-6029.

[12] Troiani, C., A.L. Eusebi and P. Battistoni (2011). Excess sludge reduction by biological way: From experimental experience to a real full-scale application, Bioresource Technol., 102 (22), pp. 10352-10358.

[13] Metcalf \& Eddy (2003). Wastewater Engineering, Treatment and Reuse, McGraw-Hill, New York.

[14] Jones R., Parker W., Khan Z., Murphy S. and Rupke M. (2007). A study of the biodegradable fraction of Sludge in aerobic and anaerobic systems. Residuals and Biosolids Management, WEF Conference, Proceedings, pp. 20-35.

[15] Sperandio M., Labelle M.A., Ramdani A., Gadbois A., Paul E., Comeau Y. and Dold P. (2013). Modelling the degradation of endogenous residue 
and "unbiodegradable" influent organic suspended solids to predict sludge production. Water Sci. Technol., 67 (4), pp. 789-796.

[16] Reichert P., (1998). AQUASIM 2.0. User Manual. Swiss Federal Institute for Environmental Science and Technology (EAWAG), Switzerland. p. 219.

[17] Fall C. and Loaiza-Navia J. (2007). Design of a Tracer Test Experience and Dynamic Calibration of the Hydraulic Model for a Full-scale WWTP by Use of AQUASIM. Water Environ. Res., 79 (8), pp. 893-900. 